\title{
¿QUÉ ES UNA CRISIS ECONÓMICA? \\ ¿CÓMO NOS AFECTA \\ Y QUÉ HACER?
}

Narsiza Monter Velasco*

\section{RESUMEN}

Este artículo es de interés actual, trata sobre la crisis económica mundial y el propósito es conocer su origen y algunas formas de afrontarla, desde el punto de vista financiero. Se usó un género literario sencillo, de tal forma que facilite su comprensión a todo tipo de lectores; basado, tanto en experiencias como en conocimientos reales (personalesprofesionales), esperando que sirva de apoyo en ésta compleja transición que atraviesa no solo nuestro país, sino el mundo entero.

\section{ABSTRACT}

This is a common interest article about the world's economic crisis and its purpose is to find out its origin and some ways of facing it, from the financial view. A simple literary register has been used in order to make it comprehensible to all kinds of readers; based either on experience or real knowledge (personal - professional), hoping it will be helpful in the complex transition faced by, not only our country, but the rest of the world.

Palabras clave: Crisis, Economía, Institución Financiera, Recesión e Inflación

Key words: Crisis, Economy, Financial Institution, Recession and Inflation 
Licenciada en Derecho con Especialidad en Derecho Civil por la Universidad La Salle Pachuca. Gerente Jurídico Hidalgo, Banco Mercantil del Norte,(Banorte).narsiza.monter.velasco@banorte.com Recibido 20-III-2009 * Aceptado 30-IV-2009 * Corregido 27-VI-2009

\section{INTRODUCCIÓN}

El desarrollo del presente artículo se enfocará principalmente a las actividades relacionadas con las instituciones financieras, sin que ello sea interpretado como una discriminación o menosprecio a otras materias y factores que también se relacionan con el tema

\section{¿QUE SE ENTIENDE POR CRISIS?}

Comienzo con una de las definiciones de crisis, misma que se puede comprender desde varias perspectivas o puntos de vista, dependiendo de la interpretación que cada uno le pretenda dar: "crisis es un estado temporal de trastorno y desorganización, caracterizado principalmente, por la incapacidad del individuo para abordar situaciones particulares utilizando métodos acostumbrados para la solución de problemas...".

(Consultahttp://www.monografias.com/trabajos /mcrisis/mcrisis. shtml,diciembre 2008).

Es menester aclarar que crisis significa al mismo tiempo peligro, pero también oportunidad.

Existen diversos tipos de crisis: personal, familiar, sentimental, económica, entre otras; en este caso, abordaré la última; enfocándolo, como ya se comentó anteriormente, al ámbito financiero.

CRISIS ECONÓMICA DE LOS AÑOS 1993- 1994. Antecedentes:

Probablemente se recuerda la famosa crisis de los años 1993-1994 y subsecuentes, en cuyo sexenio presidencial (1988-1994) se nos informaba que la economía en nuestro país era exageradamente bondadosa, creyendo, incluso que sería posible salir de los denominados países en vías de desarrollo para convertirnos en un país desarrollado. En el sexenio citado, realmente estábamos a punto del colapso en nuestra economía nacional, originada principalmente por una devaluación, consecuencia de la falta de reservas internacionales ocasionado, entre otros factores, por el enorme gasto gubernamental, sobresaliendo la inversión desmedida en infraestructura. 
Origen:

Debido a que los usuarios de servicios financieros (clientes bancarios), confiados en que sus negocios (a los cuales se les había invertido recurso derivado de créditos bancarios) serían fructuosos y les otorgarían con semejante facilidad, ganancias para liquidar dichos créditos contratados con las diversas Instituciones Bancarias, se empezaron a solicitar, autorizar, otorgar y recibir créditos con peculiar facilidad por ambas partes (cliente- banco), aclarando que, usualmente las tasas de interés que se contrataban eran variables, las cuales se incrementaron considerablemente en esos años (19931994), haciendo imposible los pagos, lo cual propició la quiebra de las Instituciones Financieras; $y$, por ende, la de todas las personas ahorradoras y, en general del país; respecto de lo cual nos podemos preguntar, ¿qué tienen que ver las Instituciones Financieras, ahorradores y empresas en la denominada crisis económica?; pues bien, el sistema bancario de un país es el reflejo principal de su economía, debido a que, si éstas cuentan con liquidez, nosotros como ahorradores podemos usar y disponer de ellos (nuestros ahorros) como mejor lo consideremos, nuestro poder adquisitivo es excelente, el dinero y la economía fluye, hacemos compras de bienes y/o servicios a las empresas que los ofrecen, pagando en tiempo y forma, lo cual hace que el empleo tenga auge, ya que son los trabajadores quienes producen los bienes y servicios que las mencionadas empresas ofrecen, siendo el empleo, primordialmente, lo que permite la calidad de vida y el ahorro, caso que no ocurre cuando las crisis nos alcanza, la cual produce la tan sonada recesión e inflación económica; que se traducen, entre otros, en la falta de empleo digno en todos los aspectos, lo que a su vez propicia la alza de la delincuencia, la corrupción y todo tipo de actividades ilícitas que se reflejan en un deterioro en el producto Inter- no Bruto, fomentando la disminución de crecimiento económico.

Recesión e inflación:

La recesión es la parte del ciclo económico en la cual existe poca actividad productora, desempleo y acumulación de inventarios que da como resultado inflación con estancamiento; por su parte, la inflación es el aumento de precios de bienes y servicios, frente a la misma capacidad de ingresos de las personas económicamente activas o la caída del poder adquisitivo frente al ofrecimiento de bienes y servicios, lo que se diferencia de la devaluación, ya que ésta última se refiere a la caída en el valor de la moneda de un país en relación con otra moneda cotizada en los mercados internacionales, como el dólar estadounidense y el euro; todas ellas, producto de las diversas crisis económicas.

Rescate bancario:

En el multicitado sexenio (para ser exactos en el año de 990), el Congreso autorizó la creación del entonces FOBAPROA -Fondo Bancario de Protección al Ahorro, el cual se creó con aportaciones de los bancos 
como un fondo para garantizar los depósitos de los ahorradores y con la finalidad de enfrentar posibles problemas financieros extraordinarios. El fondo era un fideicomiso privado y no una entidad de la administración pública federal, administrado por el Banco de México, que consistió en "inyectar" recursos del mencionado Fideicomiso a la Banca, lo que algunos denominaron "rescate bancario". Lo anterior, evitó una mayor crisis a la ocurrida y probables golpes de Estado y/o luchas como lo ocurrido en Argentina, donde los ahorradores no podían disponer de sus recursos, por la falta de liquidez de la banca (por citar un ejemplo).

Actualmente en nuestro País contamos con el Instituto para la Protección al Ahorro Bancario, mejor conocido como IPAB, que es el organismo encargado de garantizar los depósitos de los ahorradores en las Instituciones de Banca Múltiple de México hasta por los montos y previos los requisitos y trámites que en ella se establecen. Fue creado en 1999 como un organismo descentralizado de la Administración Pública Federal mediante el decreto que creó la Ley de Protección al Ahorro Bancario.

CRISIS ECONÓMICA ACTUAL Origen:

¿Cómo se origina la crisis económica actual?, debo aclarar que ésta crisis va más allá que la crisis de los años 1993-1994 a que se ha hecho referencia, ya que ésta es denominada crisis mundial, atribuible al país más poderoso del mundo; $\mathrm{y}$, como lo planteé en párrafos anteriores, tiene que ver con la banca y sus clientes acreditados, ya que es derivada de la colocación (venta) de paquetes económicos ofrecidos por dichos bancos, los cuales, debido a lo atractivo que parecían en el mercado, fueron adquiridos por diversos bancos extranjeros. Al empezar la crisis económica en Estados Unidos y tornarse imposible para os deudores el enfrentar sus obligaciones de pago (colocadas), repercutió en los activos de dichos bancos extranjeros que adquirieron los mencionados paquetes, lo que finalmente permitió la expansión desordenada de la multicitada crisis económica en los diversos continentes, misma que se vio reflejada en las Bolsas de Valores del mundo, las cuales empezaron a caer considerablemente a partir del pasado mes de Septiembre de

2008, disminuyendo el capital de los grandes inversionistas, personas físicas y morales, solicitando algunos de ellos la suspensión de pagos y especulando su probable quiebra. En los Estados Unidos de Norteamérica se otorgaron créditos hipotecarios, se dice, con tanta facilidad, que no se realizaron los estudios financieros- crediticios debidos, lo que permitió otorgar créditos a personas con bajo o incluso sin nivel adquisitivo, lo que ocasionó la mora de los clientes para con la banca, quien al no recuperar los montos correspondientes, no cuenta con liquidez para otorgar otros servicios, principalmente la retribución de la captación a los ahorradores.

Recordemos que la rentabilidad o especulación de las Instituciones de Banca Múltiple (Bancos, tales como Banamex, Bancomer, Banorte, HSBC, por mencionar algunos) es la diferencia que se obtiene entre las tasas de interés que se tienen entre la captación y 
colocación de recursos del público entre el público; además del ofrecimiento de otros servicios como son los avalúos, dispersión de nómina, cajas de seguridad; cajeros automáticos, fideicomisos, pago de servicios e impuestos, entre otras.

Rescate bancario:

La citada crisis económica originada en el país vecino del Norte, así como las probables consecuencias catastróficas que ocasionaría inicialmente en ese país, y, posteriormente en el resto del mundo, fue sometido para su análisis a los niveles de Gobierno correspondientes en los Estados Unidos, quienes autorizaron un rescate bancario por millones de dólares, similar al ocurrido en la crisis nacional comentada en párrafos anteriores; lo cual no evitó lo que actualmente es palpable: la crisis económica mundial y lo que ésta trae consigo.

Recesión económica

Aún cuando el Gobierno Norteamericano se rehusaba a aceptar su estado de recesión, al fin la aceptó públicamente a inicios del presente año (2009); es decir, los diversos medios de comunicación nacionales y extranjeros informaron que existía poca actividad productora, desempleo y acumulación de inventarios que da como resultado el aumento de precios de bienes y servicios, frente a la misma o menor capacidad de ingresos, lo cual está siendo cada vez más real y notable conforme transcurren los meses.

\section{Expansión}

Esta crisis afecta a todo el mundo sin importar si se trata de países de los denominados desarrollados o en vías de desarrollo; por tanto, nuestro país no está exento y, debido a la cercanía y relaciones económicas con los Estados Unidos de Norteamérica, se tornó realidad la siguiente muy trillada expresión: "cuando a Estados Unidos le da gripe a México le da pulmonía".

Al respecto, al inicio del presente año (2009) nuestras autoridades Financierasgubernamentales, informaban equivocadamente (maquillando la realidad, por supuesto), que nuestro país aún se encontraba de pié; sin embargo, y no obstante a que dichas autoridades aseguraban que estábamos a punto de lograr el "desenlace" de tan desagradable e inevitable factor, ocurrió lo especulado y temido por los especialistas y organismos gubernamentales u no gubernamentales. 
Debido a que la multicitada crisis económica aún no toca fondo en el mundo y en nuestro país, no debemos restarle importancia; no pre- ocupándonos, sino ocupándonos de todos y cada uno de nosotros en lo que nos corresponde en lo individual, principalmente, en nuestras finanzas, de tal forma que la afrontemos de la mejor forma posible, para lo cual se emiten las siguientes:

Recomendaciones:

A) Si eres usuario de alguna institución financiera ("Institución Financiera: en singular o plural, a las sociedades controladoras, instituciones de crédito, sociedades financieras de objeto limitado, sociedades de información crediticia, casas de bolsa, especialistas bursátiles, sociedades de inversión, almacenes generales de depósito, uniones de crédito, arrendadoras financieras, empresas de factoraje financiero, sociedades de ahorro y préstamo, casas de cambio, instituciones de seguros, sociedades mutualistas de seguros, instituciones de fianzas, administradoras de fondos para el retiro, empresas operadoras de la base de datos nacional del sistema de ahorro para el retiro, y cualquiera otra sociedad que requiera de la autorización de la Secretaría de Hacienda y Crédito Público o de cualesquiera de las Comisiones Nacionales para constituir- se y funcionar como tales y ofrecer un producto o servicio financiero a los Usuarios" (Artículo 2, fracción IV de la Ley de Protección y Defensa al Usuario de Servicios Financieros).

Si entre tus planes económicos está el contratar un servicio financiero, si se trata de un otorgamiento de crédito, lo primero que debes hacer es comparar las tasas de interés, el servicio, la atención que te brinda tu Institución de crédito y no olvidar realizar un análisis minucioso de la utilidad que obtendrás, determinando la necesidad de su contratación; si no es indispensable, no contrates deudas, recuerda que el crédito es una herramienta de bienestar; si se trata de cualquier otro servicio, compara costos y beneficios, recuerda que en las inversiones a plazo, como su nombre lo indica, tus ahorros son inamovibles por el tiempo contratado, analiza tus necesidades y prevé.

2. Todas las Instituciones Financieras que ofrezcan crédito o préstamo, tienen la obligación de informar sobre el denominado CAT que significa Costo Anual Total, el cual se obtiene sumando todos los gastos que implica la celebración de la operación, no solo los intereses que te ofrecen, sino gastos adicionales como comisiones, anualidades, entre otros.

3. Si tienes la opción de elegir, contrata tasas fijas; las de las tarjetas de crédito no son fijas y los intereses se calculan sobre saldos insolutos, es decir, sobre lo que queda como saldo o suerte principal después de que realizas un pago mínimo, cuyo monto mayor se aplica a intereses, lo que indica que aparentemente no se está respetando la tasa contratada, paga mas del mínimo o liquídalas. 
4. Contar con la autorización de una tarjeta de crédito no significa que tengas un ingreso adicional, recuerda que es algo "prestado" que debes reembolsar con intereses, gastos, comisiones y lo que implique dependiendo del banco con quien contrates, recuerda siempre tu fecha de corte (fecha hasta la cual la Institución te va a calcular y cargar intereses) y fecha límite de pago (fecha límite hasta la cual puedes realizar por lo menos el pago mínimo, con el objeto de que no incurras en mora y no te carguen gastos adicionales como gastos de cobranza e intereses moratorios, que incluso pueden llegar a ser mayores a tu pago mínimo), recuerda que el no realizar tus pagos a tiempo, da derecho a la Institución de Crédito a enviar un reporte negativo a tu buró de crédito que dañará tu historial crediticio $y$, probablemente, te incapacitará para la obtención de un crédito en el futuro que puede ser de gran utilidad.

5. Retirar efectivo de una tarjeta de crédito implica una comisión extra y retirar efectivo de una tarjeta de débito, puede implicar comisiones, máxime si se usa un cajero red que no sea de la institución bancaria que la emitió, lee tu contrato y las instrucciones que te otorgan los cajeros automáticos.

6. Cuida los esqueletos de cheques y tarjetas, recuerda que legalmente están bajo tu responsabilidad y no podrás alegar en Juicio que el Banco lo es si no diste aviso de su pérdida o robo en tiempo y forma, recuerda que todos los Bancos cuentan con un 01 800 sin costo para el cliente, en el cual se levantan reportes y/o solicitudes de aclaraciones; ten presente que éstas prescriben si no las realices debidamente, sigue correctamente las indicaciones proporcionadas.

7. No permitas que tu nombre se use para que te constituyan como acreditado (quien recibe un crédito) y tampoco prestes garantías personales como son el aval, la fianza o la obligación solidaria, puede ser que dañen tu historial crediticio o que pierdas lo que con tanto esfuerzo has logrado.

8. Contrata seguros: existen de vida, por desempleo, contra daños, contra los bienes muebles del hogar, de gastos médicos, entre otros; por otra parte, se aseguran los inmuebles, muebles (automóviles), las tarje- tas de débito y crédito, los estudios, entre otros; el banco de tu preferencia cuenta con ejecutivos especializados que te pueden recomendar alguno de acuerdo a tus necesidades. Informa a tu familia sobre los seguros contratados, recuerda que el seguro nunca te va a buscar, tú debes acudir a él; hazlo efectivo, no obstante que lleve tiempo el trámite. 
9. Si bien especular puede significar ganancia, también puede significar pérdida, debes estar muy consciente de ello.

10. Para cualquier queja, aclaración o solicitud respecto de Instituciones Financieras, existe un organismo descentralizado del Gobierno Federal denominado Comisión para la Defensa a los Usuarios de Servicios Financieros (CONDUSEF), quienes te asistirán en forma gratuita, procura asistir a ella siempre que consideres que se te ha violado un derecho y tengas lo necesario para debatirlo; ésta autoridad es incompetente para disminuciones de tasas de interés, lo cual pactaste libremente.

11. Infórmate, ocúpate y reflexiona al respecto, no gastes más de lo que tienes o puedes tener.

12. Si bien es cierto, mi interés no fue abordar la "crisis sentimental"; considero de singular relevancia emitir la siguiente: conservemos y agradezcamos nuestro empleo, realizar nuestras tareas con amor y honestidad, permite que nuestra vida (en el amplio sentido) sea mejor, debido a que no te pesará realizarlas.

\section{B) Otras:}

1. Si perdiste el empleo y alguna vez contrataste algún seguro de desempleo, es momento de hacerlos valer; acude a tu aseguradora o Institución bancaria con los documentos correspondientes.

2. Si perdiste el empleo puedes acudir a tu afore, quien tiene la obligación de atenderte e informarte sobre los diversos trámites que debes realizar para apoyarte con un porcentaje de lo ahorrado.

3. No decaigas, intenta. Probablemente no encontrarás algo igual o mejor; sin embargo, puedes ocuparte mientras tanto en otras cosas que también son buenas y productivas.

Como cualquier clase de crisis, el ocuparnos y salir de ella nos robustece, en su mayoría no suelen ser tan reales o drásticas como lo pensamos cuando estamos inmersos, no permitas que te dañe. 


\section{FUENTES DE CONSULTA}

- http://www.monografias.com/trabajos /mcrisis/mcrisis.shtml

- Ley de Protección y Defensa al Usuario de Servicios Financieros. Publicada en el Diario Oficial de la Federación el 8 de Enero de 999, cuya última reforma fue el 25 de Junio de 2009. 